\title{
Outcomes of children exposed in utero to chemotherapy for breast cancer
}

\author{
Rashmi K Murthy ${ }^{1}$, Richard L Theriault ${ }^{1}$, Chad M Barnett ${ }^{2}$, Silvia Hodge ${ }^{1}$, Mildred M Ramirez ${ }^{3}$, Andrea Milbourne ${ }^{3,4}$, \\ Sue A Rimes ${ }^{4}$, Gabriel N Hortobagyi ${ }^{1}$, Vicente Valero ${ }^{1}$ and Jennifer K Litton ${ }^{1 *}$
}

\begin{abstract}
Introduction: The incidence of breast cancer diagnosed during pregnancy is expected to increase as more women delay childbearing in the United States. Treatment of cancer in pregnant women requires prudent judgment to balance the benefit to the cancer patient and the risks to the fetus. Prospective data on the outcomes of children exposed to chemotherapy in utero are limited for the breast cancer population.
\end{abstract}

Methods: Between 1992 and 2010, 81 pregnant patients with breast cancer were treated in a single-arm, institutional review board-approved study with 5-fluorouracil, doxorubicin, and cyclophosphamide (FAC) in the adjuvant or neoadjuvant setting. Labor and delivery records were reviewed for each patient and neonate. In addition, the parents or guardians were surveyed regarding the health outcomes of the children exposed to chemotherapy in utero.

Results: In total, 78\% of the women (or next of kin) answered a follow-up survey. At a median age of 7 years, most of the children exposed to chemotherapy in utero were growing normally without any significant exposure-related toxicity or health problems. Three children were born with congenital abnormalities: one each with Down syndrome, ureteral reflux or clubfoot. The rate of congenital abnormalities in the cohort was similar to the national average of 3\%.

Conclusions: During the second and third trimesters, pregnant women with breast cancer can be treated with FAC safely without concerns for serious complications or short-term health concerns for their offspring who are exposed to chemotherapy in utero. Continued long-term follow-up of the children in this cohort is required.

Trial registration: ClinicalTrials.gov Identifier: NCT00510367. Other Study ID numbers: ID01-193, NCI-2012-01578. Registration date: 31 July 2007.

\section{Introduction}

Breast cancer is the most common malignancy associated with pregnancy; however, only $0.2 \%$ to $2.9 \%$ of all breast cancers occur during pregnancy [1,2]. As women are delaying childbearing, the incidence of breast cancer during pregnancy is increasing [3-5]. Management of breast cancer during pregnancy requires an intricate balance between using multiple modalities to effectively treat the mother and minimizing the potential toxicities for the fetus [6]. The factors that must be considered include the breast cancer subtype, the extent of disease at the time of diagnosis, the mother's general health, the proposed

\footnotetext{
* Correspondence: jlitton@mdanderson.org

'Department of Breast Medical Oncology, The University of Texas MD Anderson Cancer Center, 1515 Holcombe Boulevard, Box 1354, Houston, TX 77030, USA

Full list of author information is available at the end of the article
}

treatment plan, the health of the fetus and the gestational age at diagnosis [7].

Compared with breast cancer in nonpregnant patients, breast cancer in pregnant women is often diagnosed at a more advanced stage and is more likely to present with a large tumor size, high nuclear grade, lymph node involvement, lymphovascular invasion and hormone receptornegative status [8]. The treatment goals for pregnant patients are the same as those for nonpregnant patients: to achieve local disease control and prevent systemic recurrences [9]. Pregnancy itself does not appear to be associated with worse breast cancer outcomes [10,11]. With appropriate local and systemic therapy, women treated with chemotherapy during pregnancy have clinical outcomes that are no worse than those of nonpregnant patients matched for age and breast cancer stage [12]. 
Treatment recommendations for pregnant patients have been based upon case reports, retrospective data, case series and anecdotal evidence [13]. In selected cases, surgery may be the first therapy offered. Chemotherapy, given either neoadjuvantly or adjuvantly, is often required because most pregnant patients are young and present with biologically aggressive and/or large locally advanced tumors. When radiation therapy for breast cancer is needed, it is deferred until after childbirth to avoid radiation exposure to the fetus.

Information on the effects of antineoplastic drugs administered during pregnancy has been focused largely on fetal abnormalities (for example, spontaneous abortion, malformations, fetal intrauterine growth retardation, fetal death). The period of pregnancy during which the fetus is exposed to chemotherapy appears to be critical, as the highest risk for fetal malformation occurs during fetal organogenesis in the first trimester [14]. When chemotherapy is administered during the second and third trimesters, the reported fetal malformation rates range from $1.3 \%$ to $3.8 \%$, which are similar to the rate reported for the general population [15-17]. Anthracycline-based chemotherapy can be administered safely during the second and third trimesters $[18,19]$. There are also data accumulating that support the use of taxanes during pregnancy [20,21]. However, trastuzumab and endocrine therapy are reserved until after childbirth because of the risks of fetal complications, even when given in the second and third trimesters [16].

Although increasing evidence showing the safety and efficacy of treatment with chemotherapy for breast cancer in the second and third trimesters has emerged, the concurrent diagnosis of breast cancer and pregnancy remains a clinical and ethical challenge for the oncologist, obstetrician, pediatrician and patient. Limited data are available regarding the long-term outcomes of children exposed to chemotherapy in utero, and there are currently no specific guidelines for monitoring such children. More data about the long-term effects of gestational chemotherapy exposure are needed to guide pediatricians and other health care providers as they continue to care for children with such exposure. At the University of Texas MD Anderson Cancer Center, women with breast cancer diagnosed during pregnancy have received the same systemic chemotherapy regimen-5-flurouracil, doxorubicin and cyclophosphamide (FAC) - in the second and third trimesters since 1992 [13]. In 2006, Hahn et al. reported on the initial follow-up of children exposed to these drugs in utero and found no significant short-term complications for the majority of those children [18]. The objective of this study was to provide an update 8 years after the initial report on the acute neonatal complications and expand on the postneonatal outcomes of this cohort of children exposed to chemotherapy in utero.

\section{Methods}

Between 1992 and 2010, 81 patients who provided informed consent and met the eligibility criteria for a prospective, institutional review board (IRB)-approved trial at our institution were treated using a standardized chemotherapy regimen during the second and third trimesters of their pregnancy. The IRB at the University of Texas MD Anderson Cancer Center provided approval for this study. Patients signed an IRB-approved informed consent to be eligible for the study. No separate ethics committee approved this study outside of the institutional review board. All enrolled patients were treated in compliance with the Declaration of Helsinki. The patients received outpatient combination chemotherapy (FAC) with cyclophosphamide $\left(500 \mathrm{mg} / \mathrm{m}^{2}\right.$ intravenously on day 1 ), doxorubicin $\left(50 \mathrm{mg} / \mathrm{m}^{2}\right.$ by continuous infusion over 72 hours) and two bolus doses of 5-fluorouracil (500 $\mathrm{mg} / \mathrm{m}^{2}$ intravenously on days 1 and 4) [18]. Each cycle was given every 21 to 28 days, and therapy lasted through gestational week 35 . Other standard systemic therapies, such as trastuzumab and endocrine therapy with tamoxifen, were given after childbirth. Outcomes of the women and short-term outcomes of the children exposed in utero have been reported previously $(n=57)[13,18]$.

As part of their participation in the registry trial for the treatment of breast cancer during pregnancy, the participants also provided consent for obtaining delivery records and subsequent questionnaires that provided data for this analysis. Labor and delivery records were obtained, and relevant data were recorded and updated in a prospective manner. A health survey/questionnaire (Table 1) was sent to the parents or guardians of the children who were exposed to chemotherapy in utero to evaluate immediate and long-term outcomes. The survey was divided into two portions: neonatal outcomes and postneonatal outcomes. The survey questions covered issues related to delivery, puberty, reproductive capacity and overall health concerns. The survey was added to the study protocol in 2001, and the resultant data were collected from 2001 through 2005. The survey was sent out a second time in 2010 in an effort to capture as much data as possible. The data are included in this article. Descriptive statistics were used to report the results.

\section{Results}

Of the 81 participants, 63 patients or their next of kin (78\%) answered at least some portion of the survey regarding the child exposed to chemotherapy in utero. Of the surveys not accounted for, seven participants were lost to follow-up. The reasons for inadequate follow-up included death of study participant, a preference not to respond or the inability to identify next of kin. Eleven participants were enrolled in the study after the second round of surveys was mailed in 2010. These participants 
Table 1 Health questionnaire

\begin{tabular}{|c|c|}
\hline & uestionnaire items \\
\hline & elivery and current health status \\
\hline & $\begin{array}{l}\text { Delivery statistics: weight, weeks gestation, C-section or vaginal } \\
\text { delivery }\end{array}$ \\
\hline & $\begin{array}{l}\text { Did your child have any medical problems at the time of delivery } \\
\text { such as having fever, needing oxygen, or being admitted to a } \\
\text { special care unit, such as intensive care? }\end{array}$ \\
\hline 3 & $\begin{array}{l}\text { Did your child have any medical problems in the first month } \\
\text { after birth after being discharged home after delivery? }\end{array}$ \\
\hline & Do you consider your child to be healthy? \\
\hline 5 & Does your child have any of the following: \\
\hline & Breathing problems such as asthma \\
\hline & Heart problems such as a heart murmur \\
\hline & Stomach or other gastrointestinal problems such as heartburn \\
\hline & Bone/skeletal problems such as arthritis \\
\hline & Urinary problems (kidney or bladder problems) \\
\hline & Neurological problems (numbness, weakness) \\
\hline & Ear/nose/throat problems including hearing \\
\hline & Allergies/eczema \\
\hline & Eye/visual problems \\
\hline & evelopmental/social history \\
\hline & $\begin{array}{l}\text { If in school, has your child had any difficulties in school such as } \\
\text { requiring smaller class size, extra tutoring or one-on-one teaching? }\end{array}$ \\
\hline & $\begin{array}{l}\text { Has your child started to have any developmental changes related } \\
\text { to puberty? }\end{array}$ \\
\hline & Has your child become pregnant or fathered a child? \\
\hline & Has your child tried to conceive, but had difficulty? \\
\hline & oncerns about cancer and parenthood \\
\hline & $\begin{array}{l}\text { is section detailed the number of previous pregnancies at time } \\
\text { diagnosis, wishes for future pregnancies, Reproductive Concerns } \\
\text { ale and questions related to how pervasive the thoughts of cancer } \\
\text { e in day-to-day life. }\end{array}$ \\
\hline
\end{tabular}

who did not respond to the surveys were included in the labor and delivery data, as these data were available.

Eighty-one children were born after exposure to varying numbers of anthracycline-based chemotherapies in utero. Among the cohort, there were a total of $328 \mathrm{cy}$ cles of FAC administered (mean $=4.2$ cycles) $(N=81)$. Eighty-six percent had exposure to at least four cycles of anthracycline-based chemotherapy. Delivery data and neonatal complications are shown in Tables 2, 3 and 4, respectively. The mean gestational age at delivery was 37 weeks (range, 29 to 41 weeks). The mean birth weight overall was $2.9 \mathrm{~kg}$ (range, 1.4 to $3.9 \mathrm{~kg}$ ). Of the patients with information available regarding delivery, 33\% were delivered by cesarean section, while $67 \%$ underwent normal vaginal delivery.

Twenty-eight children were delivered preterm, defined as prior to 37 weeks' gestation. Of these, one child was delivered at 29 weeks, weighing $1.39 \mathrm{~kg}$ and requiring a
Table 2 Delivery outcomes for children exposed to chemotherapy in utero, overall

\begin{tabular}{ll}
\hline Delivery outcome & Data \\
\hline Mean gestational age at delivery, wk & $37(29$ to 41$)$ \\
Mean birth weight, $\mathrm{kg}$ & $2.9(1.3$ to 3.9$)$ \\
Type of delivery, $n(\%)$ & \\
Cesarean section & $27(33.3)$ \\
Vaginal & $54(66.7)$ \\
Chemotherapy exposure, $n(\%)$ & \\
$>4$ cycles of FAC & \\
$\leq 3$ cycles of FAC & $70(86.0)$ \\
Unknown number of cycles & $5(6.0)$ \\
\hline
\end{tabular}

${ }^{\mathrm{a}} \mathrm{FAC}$, 5-Fluorouracil, doxorubicin, and cyclophosphamide.

prolonged neonatal intensive care unit stay lasting 2 months. Another child with exposure to one cycle of anthracycline-based chemotherapy in utero was born at 32 weeks with a weight of $3.29 \mathrm{~kg}$ and required supplemental oxygen at the time of delivery. The remaining 26 preterm births occurred during gestational weeks 33 to 36. Among the preterm births, the mean birth weight $(2.8 \mathrm{~kg})$ and the mean number of chemotherapy cycles exposed to in utero (four cycles) were similar to the those in the general cohort. The majority of the preterm births were spontaneous vaginal deliveries $(n=27 ; 63 \%)$, without complications. Eleven preterm births (40\%) occurred by cesarean section, and two of the mothers required emergent procedures. One of the emergent procedures was associated with maternal heart problems and fetal distress, and the other was a breach delivery.

At delivery, 63 patients had data evaluable for neonatal complications. The following complications were noted: $17 \%(n=11)$ required extra oxygen, $2 \%(n=1)$ had subarachnoid hemorrhage, $3 \%(n=2)$ had hypoglycemia and $5 \%(n=3)$ had jaundice (Table 4). Of the 63 patients, 38 had been exposed to four or more cycles of chemotherapy in utero, and the majority (65\%) did not have any neonatal complications documented. One child with six cycles of in utero chemotherapy exposure was born with poor tone, which resolved soon after birth (not shown in Table 4). Table 4 displays the neonatal complications documented

Table 3 Delivery outcomes for children exposed to chemotherapy in utero, preterm

\begin{tabular}{ll}
\hline Delivery outcome & Result, $\boldsymbol{n}$ \\
\hline Preterm births ( $<37 \mathrm{wk})$ & 28 \\
Late preterm (32 to $36 \mathrm{wk})$ & 27 \\
Early preterm $(<32 \mathrm{wk})$ & 1 \\
Cesarean section delivery & 11 \\
Vaginal delivery & 17 \\
\hline
\end{tabular}


Table 4 Neonatal complications of children exposed to chemotherapy in utero

\begin{tabular}{|c|c|c|c|c|c|}
\hline Complication & $n(\%)$ & $\begin{array}{l}\geq 4 \text { cycles of anthracycline-based } \\
\text { in utero chemotherapy exposure, } n\end{array}$ & $\begin{array}{l}<4 \text { cycles of anthracycline-based } \\
\text { in utero chemotherapy exposure, } n\end{array}$ & $\begin{array}{l}\text { Preterm, } n \\
\text { (<37 wk) }\end{array}$ & $\begin{array}{l}\text { Term, } n \\
\text { ( } \geq 37 \mathrm{wk} \text { ) }\end{array}$ \\
\hline $\begin{array}{l}\text { Any neonatal complications } \\
\text { at delivery }\left(N=63^{\mathrm{a}}\right)\end{array}$ & $21(33)$ & 13 & 8 & 14 & 7 \\
\hline Breathing difficulties & $11(17)$ & 9 & 2 & 7 & 4 \\
\hline Subarachnoid hemorrhage & $1(2)$ & 1 & 0 & 1 & - \\
\hline Jaundice & $3(5)$ & 2 & 1 & 2 & 1 \\
\hline Low heart rate & $2(3)$ & 1 & 1 & 1 & 1 \\
\hline Hypoglycemia & $2(3)$ & 0 & 2 & 1 & 1 \\
\hline Abnormal temperature & $2(3)$ & 2 & 0 & 1 & 1 \\
\hline NICU/hospitalizations $\left(N=63^{\mathrm{a}}\right)$ & $9(14)$ & 5 & 4 & 4 & 5 \\
\hline Prolonged NICU stay ${ }^{\mathrm{b}}$ (>1 mo) & $2(3)$ & 0 & 2 & $2^{c}$ & - \\
\hline $\begin{array}{l}\text { Temporary hospital or } \\
\text { NICU stay ( } \leq 14 \text { days) }\end{array}$ & $7(11)$ & 5 & 2 & 2 & 5 \\
\hline
\end{tabular}

2-month stay due to being born at 29 weeks. The other child was delivered at 35 weeks.

according to the number of patients exposed to four or more cycles of in utero chemotherapy and according to whether the delivery was preterm or at term. Of the 21 patients with neonatal complications, $62 \%$ were exposed to at least four cycles of chemotherapy in utero. Seventeen percent of neonates had breathing difficulties at birth. Among the preterm neonates with respiratory difficulty, almost all the cases were due to premature lung development. These neonates required at most supplemental oxygen by nasal cannula. One preterm neonate did have documented respiratory distress syndrome. Of the term neonates, one had just nasal flaring and one had transient tachypnea requiring oxygen for 24 hours. Another term neonate had nuchal cord and required cardio-pulmonary resuscitation because of this and one other had labored breathing with supplemental oxygen and therefore was intubated but subsequently weaned off within 8 hours. Eighty-two percent of neonates with breathing difficulties and fifty-six percent requiring temporary or prolonged hospital stays had been exposed to four or more cycles of chemotherapy in utero. Of the entire cohort $(N=81)$, congenital abnormalities remained the same as reported in 2006 [18]: one child was born with Down syndrome, one with clubfoot and one with ureteral reflux (hydronephrosis).

Postneonatal outcomes are given in Table 5, which shows health conditions reported in the survey and the prevalence of these conditions in the general population. The median age of the children at the time of survey completion was 7 years (range, $<1$ to 21 years). Of the 50 participants who responded to the portion of the survey evaluating postneonatal outcomes, 13 (26\%) were between 13 and 22 years old. The remainder had children who were school-aged (ages 3 to 12 years; $n=19$ ) or infants (0 2 years of age; $n=17$ ). The majority of survey responders considered their children to be healthy overall, and only minor health issues were reported, as noted in Table 5. Of note, 31 patients reported a health issue, and $61 \%$ of these 31 patients had extensive in utero chemotherapy exposure (four or more cycles). For each data point of the health issues reported, the prevalence in the general population has been noted in Table 5 as a reference for comparison as well as the number of those with each health concern who have been exposed to four or more cycles of anthracycline-based chemotherapy in utero. Nineteen children were described as being healthy, and $47 \%$ of these had in utero exposure to four or more cycles of anthracycline-based chemotherapy. Twelve percent of the survey responders indicated that their children had developmental milestone delays. Three of these were childhood language delays. There were no significant cognitive abnormalities reported in the children. Of the 37 children who were reported to be enrolled in preschool through college, four reported having any difficulties in school. Three children, one of whom had recently graduated from college, were reported to have reading delays, and one child in seventh grade was reported to have difficulty with attention span. Eleven children had advanced past the seventh grade, and the majority $(90 \% ; n=10)$ reported no difficulties. There was one child enrolled at the time in a college bachelor's degree program. Other health problems reported by survey responders included 18 children with allergies and/or eczema (36\%), 5 with asthma (10\%), 1 with migraine headaches and 1 with absence seizures. Only allergies and/or eczema occurred at a prevalence higher than the general population reference rate. Sixtyseven percent of those with allergies and/or eczema had been exposed to more than four cycles of anthracyclinebased chemotherapy in utero, and four of the five children who developed asthma also had more extensive 
Table 5 Postneonatal outcomes of children exposed to chemotherapy in utero

\begin{tabular}{|c|c|c|c|}
\hline Reported outcome & $n / N(\%)$ & $\begin{array}{l}\geq 4 \text { cycles of anthracycline-based in utero } \\
\text { chemotherapy exposure, } n / N(\%)\end{array}$ & Population prevalence, $\%$ [reference] \\
\hline Child considered healthy & $49 / 50(98)$ & - & - \\
\hline Developmental milestone delays & $6 / 50(12)$ & $2 / 6(33)$ & $10[22]$ \\
\hline Difficulties in school ${ }^{a}$ & $4 / 37(11)$ & $3 / 4(75)$ & 6-11 [22] \\
\hline Reported health concerns & $31 / 50(62)$ & 19/31 (61) & - \\
\hline Allergies/eczema & $18 / 50(36)$ & $12 / 18(67)$ & 11 to $25[22]$ \\
\hline Asthma/breathing & $5 / 50(10)$ & $4 / 5(80)$ & $13[22]$ \\
\hline Vision & $8 / 50(16)$ & $5 / 8(63)$ & $14[22]$ \\
\hline Heart murmur ${ }^{\mathrm{b}}$ & $1 / 50(2)$ & - & $1.3[23]$ \\
\hline "Lazy eye" & $2 / 50(4)$ & $1 / 2(50)$ & 1.6 to $3.6[24]$ \\
\hline Absence seizures $^{c}$ & $1 / 50(2)$ & $1 / 1(100)$ & $<1[25]$ \\
\hline$E N T^{d}$ & $4 / 50(8)$ & $3 / 4(75)$ & $\mathrm{HL},<1 ; \mathrm{ROM}, 18$ to $26^{\mathrm{d}}[26]$ \\
\hline $\mathrm{GERD}^{\mathrm{e}}$ & $2 / 50(6)$ & $2 / 2(100)$ & 5 to $67^{f}[27]$ \\
\hline
\end{tabular}

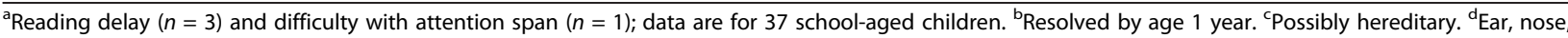
and throat (ENT) includes recurrent otitis media (ROM; $n=2)$, sinus problems $(n=1)$ and hearing deficit $(\mathrm{HL} ; n=1)$. ${ }^{\mathrm{G}} \mathrm{Gastroesophageal}$ reflux disease.

fVaries according to age.

chemotherapy exposure in utero. Furthermore, of the five children diagnosed with asthma, three had been born preterm and had breathing difficulties secondary to prematurity at birth. Ear, nose, and throat (ENT) issues were reported in $8 \%$ of children. One child was reported to have a hearing deficit and had exposure to six cycles of chemotherapy in utero. The other ENT concerns included sinus problems and recurrent otitis media, with one of these individuals requiring a myringotomy. The majority of survey respondents informed us that their children had not experienced changes related to puberty; only $24 \%(n=12)$ of children had encountered pubertal changes. It is important to note, however, that only 13 children were of pubertal age (age 13 years and older). The mean age of puberty onset was 11 years (range, 10 to 13 years), and only one child was noted to have precocious hair growth at age 4 years. There are not yet any offspring of the children.

\section{Discussion}

Our data indicate that treating women with anthracyclinebased systemic chemotherapy for breast cancer during the second and third trimesters of pregnancy can be administered without significant impairment of the health of their offspring at delivery or into childhood compared with children in the general population. To date, limited data exist regarding potential health concerns for children exposed to chemotherapy in utero. Hahn et al. reported in 2006 on the presentation, treatment and outcomes of the first 57 pregnant women treated according to study protocol. The authors reported the outcomes of children who were exposed to chemotherapy in utero; and they found the majority of the children to be healthy and without significant developmental problems [18]. The German Breast Group enrolled 413 pregnant women with early-stage breast cancer in a prospective registry study and found that the statistically insignificant increased incidence of low birth weights and obstetrical complications observed was linked to premature delivery rather than to in utero chemotherapy exposure during the second and third trimesters [19]. Furthermore, Amant et al. investigated children who were prenatally exposed to any maternal cancer staging and treatment, including chemotherapy, and found no impairment in the general health or growth of these children. Specifically, there were no associations with increased central nervous system, cardiac or auditory toxicity [28].

In the present study, we found that, at a median age of 7 years, children who were exposed to anthracycline-based chemotherapy in utero were growing well, with no significant toxic effects observed related to chemotherapy exposure. There were three children born with congenital abnormalities, which were Down syndrome, ureteral reflux and clubfoot. The child with Down syndrome was born to a 32-year-old woman. The rate of congenital abnormalities in our population is similar to the US average rate of approximately 3\% [15]. The chief long-term health concerns were allergies and/or eczema, which occurred more commonly in the children in our study than currently reported in the general population. The majority of patients reporting allergies and/or eczema were exposed to four or more cycles of anthracycline-based chemotherapy in utero; however, this finding may be the result of generalized overreporting. There have been no significant delays reported in puberty. To determine whether more extensive in utero chemotherapy exposure translates to worse health outcomes overall will require more prolonged follow-up and a prospective study with more objective data. It is 
reassuring that in the current era, most women are likely to receive four cycles of FAC in total, with perhaps less being given during the in utero period, depending on the timing of the diagnosis of breast cancer during the pregnancy and the timing of the surgical intervention. Continuing to follow cohorts of children such as these, along with multi-institutional and multinational collaborations, are needed to further address these concerns for the children, especially as they mature into adults.

Our results support previous efforts to evaluate whether children of cancer patients encounter any late adverse health effects due to in utero chemotherapy exposure. In the 457 studies reviewed in the National Toxicology Program monograph (2013) [29], 60\% of the children exposed to gestational chemotherapy had follow-up data available. Normal growth and development were reported for all; however, most of the children were not evaluated beyond year 2 of life. Other investigators have performed longerterm evaluations of children exposed to chemotherapy in utero. The largest dataset to date consists of 84 pregnant women who were treated for hematologic malignancies and whose children and grandchildren $(n=12)$ participated in a study for follow-up of the long-term effects of the treatment. At a median follow-up of 18.7 years, there were no cases of leukemia and no long-term ill effects related to physical health, growth or development among the children exposed to chemotherapy in utero or among their offspring [30].

The main limitations of the present study include its small sample size, subjective nature (via questionnaire) and short follow-up period. The numbers of older and postpubertal children are small. The outcomes of the exposed children were assessed through a survey distributed to the children's parents or guardians. Although the response rate for this study was satisfactory, we could not assess all eligible children. Behavioral and emotional outcomes of the children might be better addressed by a survey directed to the children themselves. Although the survey form was written at a low literacy level, the educational backgrounds of the respondents may have varied and thus may have contributed to the number of incomplete surveys. Additionally, it might be effective to minimize free text and create a standardized case report form [19] for data collection, which could be expanded to capture data from other cohorts in centers across the United Stataes. Furthermore, the results may have been more reliably gained by using an objective format such as pediatricians' records or chart reviews as compared to questionnaires. It will be important to continue to follow these patients in the future and obtain more objective data for them, such as records from pediatric visits and hospitalizations. Additionally, the follow-up period was short, as the median age of the children was 7 years. Continued followup of this growing cohort is essential. It will be valuable to note the incidence of chronic health conditions, cancer and fertility issues as the children enter puberty and adulthood and of labor and/or delivery complications as the children in the study have children of their own.

\section{Conclusions}

This cohort of children exposed to chemotherapy in utero appeared to be doing well, with no trend to indicate a higher rate of serious medical problems than that seen in the general population. This is an important prospective single-institution study of outcomes of children exposed in utero to anthracycline-based chemotherapy for breast cancer. Pregnant women and physicians can be reassured that treating breast cancer during the second and third trimesters with anthracycline-based chemotherapy does not jeopardize the health outcomes of the developing fetus. No specific recommendations regarding health monitoring for these children outside of the recommendations for the general population are supported by these data. Potential concerns may arise and will need to be followed in this cohort as well as others. These concerns include future childbirth and fertility issues as more offspring reach puberty, as well as the cancer incidence in the population exposed to chemotherapy in utero. Future exploration of cognitive impairment, high school graduation rates and college attendance rates, as well as continued long-term follow-up of this and other cohorts, is needed to provide more information to parents and pediatricians.

\section{Abbreviations}

ENT: Ear, nose and throat; FAC: 5-Fluorouracil, doxorubicin, and cyclophosphamide; GERD: Gastroesophageal reflux disease; IRB: Institutional review board; NICU: Neonatal intensive care unit.

\section{Competing interests}

The authors declare that they have no competing interests.

\section{Authors' contributions}

RM participated in data analysis and interpretation and drafted the manuscript. $\mathrm{CB}, \mathrm{MR}, \mathrm{AM}, \mathrm{SR}, \mathrm{SH}, \mathrm{GH}$ and W contributed to data acquisition, analysis and interpretation. RT and $\lrcorner \mathrm{L}$ conceived of the study and participated in its design and coordination, data analysis, and interpretation of data. RT, CB, MR, AM, W, $\mathrm{GH}$ and $J \mathrm{~L}$ reviewed the manuscript critically and revised it for important intellectual content. All authors read and approved the final manuscript.

\section{Author details}

${ }^{1}$ Department of Breast Medical Oncology, The University of Texas MD Anderson Cancer Center, 1515 Holcombe Boulevard, Box 1354, Houston, TX 77030, USA. ${ }^{2}$ Division of Pharmacy, The University of Texas MD Anderson Cancer Center, 1515 Holcombe Boulevard, Houston, TX 77030, USA.

${ }^{3}$ Department of Obstetrics/Gynecology, The University of Texas Health Science Center, 6431 Fannin Street, Houston, TX 77030, USA. ${ }^{4}$ Department of Gynecologic Oncology and Reproductive Medicine, The University of Texas MD Anderson Cancer Center, 1515 Holcombe Boulevard, Unit 1362, Houston, TX 77030, USA.

Received: 15 May 2014 Accepted: 8 December 2014

Published online: 30 December 2014

\section{References}

1. Wallack MK, Wolf JA Jr, Bedwinek J, Denes AE, Glasgow G, Kumar B, Meyer JS, Rigg LA, Wilson-Krechel S: Gestational carcinoma of the female breast. Curr Probl Cancer 1983, 7:1-58. 
2. Lethaby AE, O'Neill MA, Mason BH, Holdaway IM, Harvey VJ, the Auckland Breast Cancer Study Group: Overall survival from breast cancer in women pregnant or lactating at or after diagnosis. Int J Cancer 1996, 67:751-755.

3. Andersson TM, Johansson AL, Hsieh CC, Cnattingius S, Lambe M: Increasing incidence of pregnancy-associated breast cancer in Sweden. Obstet Gynecol 2009, 114:568-572.

4. Martin JA, Hamilton BE, Ventura SJ, Osterman MJK, Kirmeyer S, Mathews TJ, Wilson EC: Births: final data for 2009. Natl Vital Stat Rep 2011, 60(1):1-70.

5. Matthews TJ, Hamilton BE: Delayed childbearing: more women are having their first child later in life, NCHS Data Brief (No. 21). Hyattsville, MD: National Center for Health Statistics; 2009.

6. Theriault R, Hahn K: Management of breast cancer in pregnancy. Curr Oncol Rep 2007, 9:17-21.

7. Gwyn K: Children exposed to chemotherapy in utero. J Nat/ Cancer Inst Monogr 2005, 34:69-71.

8. Middleton LP, Amin M, Gwyn K, Theriault R, Sashin A: Breast carcinoma in pregnant women: assessment of clinicopathologic and immunohistochemical features. Cancer 2003, 98:1055-1060.

9. Litton JK, Theriault RL: Breast cancer and pregnancy: current concepts in diagnosis and treatment. Oncologist 2010, 15:1238-1247.

10. Amant F, von Minckwitz G, Han SN, Bontenbal M, Ring AE, Giermek J, Wildiers H, Fehm T, Linn SC, Schlehe B, Neven P, Westenend PJ, Müller V, Van Calsteren K, Rack B, Nekliludova V, Harbeck N, Untch M, Witteveen PO, Schwedler K, Thomssen C, Van Calster B, Loibl: Prognosis of women with primary breast cancer diagnosed during pregnancy: results from an international collaborative study. J Clin Oncol 2013, 31:2532-2539.

11. Beadle BM, Woodward WA, Middleton LP, Tereffe W, Strom EA, Litton JK, Meric-Bernstam F, Theriault RL, Buchholz TA, Perkins GH: The impact of pregnancy on breast cancer outcomes in women $\leq 35$ years. Cancer 2009, 115:1174-1184.

12. Litton JK, Warneke CL, Hahn KM, Palla SL, Kuerer HM, Perkins GH, Mittendorf EA, Barnett C, Gonzalez-Angulo AM, Hortobágyi GN, Theriault RL: Case control study of women treated with chemotherapy for breast cancer during pregnancy as compared with nonpregnant patients with breast cancer. Oncologist 2013, 18:369-376.

13. Berry DL, Theriault RL, Holmes FA, Parisi VM, Booser DJ, Singletary SE, Buzdar $\mathrm{AU}$, Hortobagyi GN: Management of breast cancer during pregnancy using a standardized protocol. J Clin Oncol 1999, 17:855-861.

14. Ring AE, Smith IE, Jones A, Shannon C, Galani E, Ellis PA: Chemotherapy for breast cancer during pregnancy: an 18-year experience from five London teaching hospitals. J Clin Oncol 2005, 23:4192-4197.

15. Centers for Disease Control and Prevention, National Center for Health Statistics: Birth Defects: Data \& Statistics. [http://www.cdc.gov/ncbddd/ birthdefects/data.html] (accessed 5 January 2015).

16. Cardonick E, Dougherty R, Grana G, Gilmandyar D, Ghaffar S, Usmani A: Breast cancer during pregnancy: maternal and fetal outcomes. Cancer J 2010, 16:76-82.

17. Doll DC, Ringenberg QS, Yarbro JW: Antineoplastic agents and pregnancy. Semin Oncol 1989, 16:337-346.

18. Hahn KM, Johnson PH, Gordon N, Kuerer H, Middleton L, Ramirez M, Yang W, Perkins G, Hortobagyi, Theriault RL: Treatment of pregnant breast cancer patients and outcomes of children exposed to chemotherapy in utero. Cancer 2006, 107:1219-1226.

19. Loibl S, Han SN, von Minckwitz G, Bontenbal M, Ring A, Giermek J, Fehm T, Van Calsteren K, Linn SC, Schlehe B, Gziri MM, Westenend PJ, Müller V, Heyns L, Rack B, Van Calster B, Harbeck N, Lenhard M, Halaska MJ, Kaufmann M, Nekljudova $V$, Amant F: Treatment of breast cancer during pregnancy: an observational study. Lancet Oncol 2012, 13:887-896.

20. Mir O, Berveiller P, Goffinet F, Treluyer JM, Serreau R, Goldwasser F, Rouzier $\mathrm{R}$ : Taxanes for breast cancer during pregnancy: a systematic review. Ann Oncol 2010, 21:425-426.

21. Cardonick E, Bhat A, Gilmandyar D, Somer R: Maternal and fetal outcomes of taxane chemotherapy in breast and ovarian cancer during pregnancy: case series and review of the literature. Ann Oncol 2012, 23:3016-3023.

22. Center for Disease Control and Prevention. National Center for Health Statistics. Vitalstats. http://www.cdc.gov/nchs/vitalstats.htm Accessed: 5/25/2011.

23. Lardhi AA: Prevalence and clinical significance of heart murmurs detected in routine neonatal examination. J Saudi Heart Assoc 2010, 22:25-27.

24. Simons K: Amblyopia characterization, treatment, and prophylaxis. Surv Ophthalmol 2005, 50:123-166.
25. Jallon P, Latour P: Epidemiology of idiopathic generalized epilepsies. Epilepsia 2005, 46(Suppl 9):10-14.

26. Lanphear BP, Byrd RS, Auinger P, Hall CB: Increasing prevalence of recurrent otitis media among children in the United States. Pediatrics 1997, 99:E1.

27. Nelson SP, Chen EH, Syniar GM, Christoffel KK, the Pediatric Practice Research Group: Prevalence of symptoms of gastroesophageal reflux during childhood: a pediatric practice-based survey. Arch Pediatr Adolesc Med 2000, 154:150-154.

28. Amant F, Van Calsteren K, Halaska MJ, Gziri MM, Hui W, Lagae L, Willemsen MA, Kapusta L, Van Calster B, Wouters H, Heyns L, Han SN, Tomek V, Mertens L, Ottevanger PB: Long-term cognitive and cardiac outcomes after prenatal exposure to chemotherapy in children aged 18 months or older: an observational study. Lancet Oncol 2012, 13:256-264.

29. National Toxicology Program, US Department of Health and Human Services: NTP Monograph: Developmental Effects and Pregnancy Outcomes Associated with Cancer Chemotherapy Use during Pregnancy. Research Triangle Park, NC: National Institute of Environmental Health Sciences; 13 May 2013.

30. Avíles A, Neri N: Hematological malignancies and pregnancy: a final report of 84 children who received chemotherapy in utero. Clin Lymphoma 2001, 2:173-177.

\section{Submit your next manuscript to BioMed Central and take full advantage of:}

- Convenient online submission

- Thorough peer review

- No space constraints or color figure charges

- Immediate publication on acceptance

- Inclusion in PubMed, CAS, Scopus and Google Scholar

- Research which is freely available for redistribution

Submit your manuscript at www.biomedcentral.com/submit
C) BioMed Central 